\title{
New possibilities for control of American powdery mildew (Sphaerotheca mors-uvae)
}

\author{
Nowe możliwości zwalczania amerykańskiego mączniaka agrestu \\ (Sphaerotheca mors-uvae)
}

\author{
Agata Broniarek-Niemiec
}

\begin{abstract}
Summary
American powdery mildew (Sphaerothec amors-uvae) is one of the most serious diseases of gooseberry and black currant. Only a few fungicides are registered to control this disease. Therefore, searching for new protection methods is of a special value. In 2010-2012, the effectiveness of the biological product AQ 10 WG containing $5 \times 10^{9}$ spores/g of fungus Ampelomyces quisqualis and Solfan PK fertilizer ( $49 \%$ potassium as $\mathrm{K}_{2} \mathrm{O}$ and $25 \%$ phosphorus as $\mathrm{P}_{2} \mathrm{O}_{5}$ ) were studied. In the case of gooseberry cultivar White Triumph both tested compounds limited the severity of disease on shoots and fruits by 70 to $93 \%$. On black currant cultivar Ben Lomond the product AQ 10 WG reduced the infection of shoots in about $60 \%$, and Solfan PK by more than $71 \%$. The tested products revealed a good efficacy in the control of American powdery mildew. In the protection of black currants and gooseberry the effectiveness of these products was the same or lower than standard fungicides (Nimrod 250 EC, Score 250 EC, Signum 33 WG and Topsin M 500 SC).
\end{abstract}

Key words: American gooseberry mildew, control, biological methods, fertilizers

\section{Streszczenie}

Amerykański mączniak agrestu (Sphaerotheca mors-uvae) jest jedną z najgroźniejszych chorób agrestu i porzeczki czarnej. Do jej zwalczania zarejestrowanych jest zaledwie kilka fungicydów, co stwarza konieczność poszukiwania nowych metod ochrony. W latach 2010-2012 oceniano efektywność preparatu biologicznego AQ 10 WG zawierającego $5 \times 10^{9}$ zarodników/g grzyba Ampelomyces quisqualis i nawozu Solfan PK (49\% potasu w formie $\mathrm{K}_{2} \mathrm{O}$ i $25 \%$ fosforu w formie $\mathrm{P}_{2} \mathrm{O}_{5}$ ). Zarówno biopreparat, jak i nawóz ograniczyły nasilenie choroby na agreście odmiany Biały Triumf na pędach oraz na owocach od 70 do $93 \%$. W przypadku porzeczki czarnej odmiany Ben Lomond preparat AQ 10 WG ograniczył porażenie pędów o około 60\%, a nawóz Solfan PK o ponad 71\%. Efektywność testowanych preparatów w ograniczaniu amerykańskiego mączniaka agrestu była wysoka i taka sama lub niższa od skuteczności fungicydów standardowych (Nimrod 250 EC, Score 250 EC, Signum 33 WG i Topsin M 500 SC).

Słowa kluczowe: amerykański mączniak agrestu, zwalczanie, metody biologiczne, nawozy

\author{
Instytut Ogrodnictwa \\ Pracownia Fitopatologii Sadowniczej \\ Pomologiczna 18, 96-100 Skierniewice \\ agata.broniarek@inhort.pl
}




\section{Wstęp / Introduction}

Amerykański mączniak agrestu [Sphaerotheca morsuvae (Schwein.) Berk. et Curt.)] jest jedną $\mathrm{z}$ najgroźniejszych chorób porzeczki czarnej i agrestu. Choroba występuje corocznie, w dużym nasileniu na podatnych odmianach porzeczki czarnej (Ben Lomond, Ben Nevis, Ceres) oraz na powszechnie uprawianej odmianie agrestu Biały Triumf.

Na porzeczce porażane są liście i pędy, a na agreście choroba wyrządza poważne szkody również na owocach. Do zwalczania amerykańskiego mączniaka agrestu zarejestrowanych jest zaledwie kilka fungicydów (Broniarek-Niemiec i Bielenin 2010). Poszukuje się nowych możliwości zwalczania choroby. Jedną z metod alternatywnych jest wykorzystanie naturalnie występujących organizmów antagonistycznych wobec sprawców chorób. Najlepiej poznanym nadpasożytem zasiedlającym grzyby, między innymi z rzędu Erysiphales, jest Ampelomyces quisqualis Ces., grzyb z klasy Coelomycetes (Adamska i Czerniawska 2010). Jego strzępki rozwijają się w grzybni, oidiach i kleistotecjach żywiciela, redukując zarodnikowanie oraz niszcząc kolonie.

Czynnikiem wspomagającym ochronę chemiczną przed agrofagami mogą być również nawozy dolistne oparte na węglanie i fosforanie potasu. Dane literaturowe wskazują na wysoką skuteczność tych związków w zwalczaniu wielu chorób grzybowych, głównie mączniaków. Działanie tych związków polega na silnym odwodnieniu i deformacji strzępek, trzonków konidialnych oraz zarodników konidialnych grzybów patogenicznych (Clement i wsp. 1994; Fallik i wsp. 1997; Wojdyła i wsp. 2010a).

Celem badań była ocena skuteczności działania preparatu biologicznego AQ $10 \mathrm{WG}$ i nawozu dolistnego Solfan PK w zwalczaniu amerykańskiego mączniaka agrestu na plantacjach porzeczki czarnej i agrestu.

\section{Materiały i metody / Materials and methods}

Oceniano skuteczność preparatu biologicznego AQ 10 WG zawierającego $5 \times 10^{9}$ zarodników/g Ampelomyces quisqualis oraz nawozu Solfan PK zawierającego 49\% potasu $\mathrm{w}$ formie $\mathrm{K}_{2} \mathrm{O}$ i $25 \%$ fosforu $\mathrm{w}$ formie $\mathrm{P}_{2} \mathrm{O}_{5}$. Doświadczenia polowe przeprowadzono w latach 2010 i 2012, na plantacjach agrestu odmiany Biały Triumf, a w latach 2011 i 2012 na plantacjach czarnej porzeczki odmiany Ben Lomond. Doświadczenia założono w układzie losowanych poletek, w 4 powtórzeniach po 10 krzewów na poletku. W każdym sezonie wykonano po 5 zabiegów: pierwszy przed kwitnieniem, kolejne po kwitnieniu, przeciętnie, co 7-13 dni. Dla porównania zastosowano fungicydy standardowe: Score $250 \mathrm{WC}$, Nimrod $250 \mathrm{EC}$, Topsin M 500 SC lub Signum 33 WG. Biologiczną efektywność badanych preparatów w zwalczaniu amerykańskiego mączniaka agrestu oceniano na podstawie liczby pędów, na których wystąpiły objawy mączniaka na liściach lub owocach. Na agreście obserwacje przeprowadzono tuż przed zbiorem owoców oceniając oddzielnie porażenie liści i owoców na pędach. Natomiast na porzeczce czarnej oceniano dwukrotnie (przed i po zbiorze owoców) porażenie liści na 100 losowo wybranych pędach, w 4 powtórzeniach. Zastosowano następującą skalę bonitacyjną: 0 - liście/owoce zdrowe, $1-1-6 \%$ powierzchni liści/owoców pokrytej nalotem, $2-6-15 \%$, $3-15-25 \%, 4-25-55 \%, 5$ - powyżej 55\%. Wyniki opracowano statystycznie metodą analizy wariancji, którą dla danych wyrażonych w procentach przeprowadzono na wartościach przekształconych według funkcji Blissa. Różnice między średnimi oceniano przy użyciu testu Newmana-Keuls'a przy poziomie istotności 5\%.

\section{Wyniki i dyskusja / Results and discussion}

Badania przeprowadzone w latach 2010 i 2012 r. wykazały, że preparat biologiczny AQ 10 WG oraz nawóz Solfan PK skutecznie chroniły pędy, liście i owoce agrestu przed amerykańskim mączniakiem agrestu. W warunkach dużego nasilenia choroby, preparat AQ $10 \mathrm{WG}$ ograniczał porażenie pędów w 91,5 i $69,5 \%$, a nawóz Solfan PK w 86,7 i 87,9\% odpowiednio w pierwszym i drugim roku badań. Efektywność biopreparatu i nawozu, w pierwszym roku badań, była taka sama, jak fungicydów standardowych Nimrod 250 EC i Score 250 EC oraz wyższa od efektywności fungicydu Topsin M 500 SC. Natomiast w drugim roku badań skuteczność preparatu AQ $10 \mathrm{WG}$ była istotnie niższa od preparatów standardowych, a skuteczność nawozu Solfan PK była taka sama, jak fungicydu Score $250 \mathrm{EC}$ i istotnie niższa niż fungicydu Nimrod 250 EC. Badane produkty skutecznie ograniczały również mączniaka na owocach agrestu. Efektywność preparatu AQ 10 WG wynosiła odpowiednio 86,9 i 93,4\%, a nawozu Solfan PK 79,2 i 78\%, odpowiednio w 2010 i 2012 r. Skuteczność biopreparatu i nawozu w ograniczaniu mączniaka na owocach agrestu była porównywalna do efektywności fungicydów standardowych (tab. 1).

W latach 2011 i 2012, w warunkach wysokiego nasilenia amerykańskiego mączniaka agrestu na porzeczce czarnej preparat AQ $10 \mathrm{WG}$ i nawóz Solfan PK skutecznie ograniczały chorobę. W obu latach badań, w pierwszym terminie oceny, wykonanym tuż przed zbiorem owoców, efektywność biopreparatu wynosiła ponad $60 \%$, a nawozu - ponad $76 \%$ i była niższa od fungicydów standardowych: Nimrod 250 EC, Score 250 EC i Signum 33 WG. $\mathrm{W}$ drugim terminie oceny wykonanym około 3 tygodnie po zbiorze owoców, efektywność preparatu AQ 10 WG w ochronie pędów wynosiła ponad 58\%, a nawozu Solfan PK - ponad $71 \%$ i była taka sama lub niższa od efektywności zastosowanych fungicydów (tab. 2).

W literaturze podaje się, że związki wchodzące w skład nawozu Solfan PK, stosowane pojedynczo wykazuja wysoką skuteczność w zwalczaniu mączniaków prawdziwych na różnych roślinach. Fosforan monopotasowy charakteryzował się dobrą skutecznością w ochronie róż przed mączniakiem prawdziwym (Reuveni i wsp. 1994). Również w badaniach Wojdyły i wsp. (2010b) po 2- i 4-krotnym opryskiwaniu róż nawozem Solfan PK stwierdzano istotne zahamowanie rozwoju choroby. Stopień porażenia pędów róży był odpowiednio 3,5- oraz 7,4-krotnie niższy niż na krzewach kontrolnych, a skuteczność nawozu była taka sama, jak w przypadku fungicydu Domark 100 EC. Ponadto wykazano wysoką 
Tabela 1. Skuteczność fungicydów i nowych produktów w zwalczaniu amerykańskiego mączniaka agrestu (S. mors-uvae) na agreście Table 1. The effectiveness of fungicides and new products in control of American powdery mildew (S. mors-uvae) on gooseberry

\begin{tabular}{|c|c|c|c|c|c|c|c|}
\hline $\begin{array}{l}\text { Kombinacje } \\
\text { Treatments }\end{array}$ & $\begin{array}{l}\text { Dawka } \\
\text { na } 1 \text { ha } \\
\text { Dose } \\
\text { per } 1 \text { ha }\end{array}$ & $\begin{array}{c}\text { Powierzchnia } \\
\text { liści zajęta } \\
\text { przez grzyb } \\
w \% \\
\text { Surface of } \\
\text { leaves covered } \\
\text { by fungus } \\
\text { in } \%\end{array}$ & $\begin{array}{l}\text { Procent } \\
\text { porażonych } \\
\text { pędów } \\
\text { Per cent } \\
\text { of infected } \\
\text { shoots }\end{array}$ & $\begin{array}{c}\text { Efektywność } \\
\text { Effectiveness } \\
{[\%]}\end{array}$ & \begin{tabular}{|c|} 
Powierzchnia \\
owoców zajęta \\
przez grzyb \\
w \% \\
Surface of fruits \\
covered by \\
fungus \\
in $\%$
\end{tabular} & $\begin{array}{l}\text { Procent pędów } \\
\text { z porażonymi } \\
\text { owocami } \\
\text { Per cent of } \\
\text { shoots with } \\
\text { infected fruits }\end{array}$ & $\begin{array}{c}\text { Efektywność } \\
\text { Effectiveness } \\
{[\%]}\end{array}$ \\
\hline \multicolumn{7}{|c|}{2010} & \\
\hline Kontrola-Check & & $33,80 \mathrm{c}$ & $96,78 \mathrm{c}$ & - & $19,72 \mathrm{c}$ & $93,74 \mathrm{e}$ & - \\
\hline AQ10 WG & $70 \mathrm{~g}$ & $0,27 \mathrm{a}$ & $8,20 \mathrm{a}$ & 91,5 & $0,48 \mathrm{a}$ & $12,26 \mathrm{a}$ & 86,9 \\
\hline Solfan PK & $0,5 \%$ & $0,45 \mathrm{a}$ & $12,9 \mathrm{a}$ & 86,7 & $0,66 \mathrm{a}$ & $19,49 \mathrm{bc}$ & 79,2 \\
\hline Nimrod 250 EC & 1,51 & $0,33 \mathrm{a}$ & $9,59 \mathrm{a}$ & 90,1 & $0,57 \mathrm{a}$ & $13,69 \mathrm{a}$ & 85,4 \\
\hline Score 250 EC & 0,21 & $0,36 \mathrm{a}$ & $11,46 \mathrm{a}$ & 88,2 & $0,48 \mathrm{a}$ & $15,39 \mathrm{abc}$ & 83,6 \\
\hline Topsin M $500 \mathrm{SC}$ & 1,51 & $2,55 \mathrm{~b}$ & $58,11 \mathrm{~b}$ & 40,0 & $2,34 \mathrm{~b}$ & $53,01 \mathrm{~d}$ & 43,4 \\
\hline \multicolumn{8}{|c|}{2012} \\
\hline Kontrola-Check & & $22,20 \mathrm{~d}$ & $95,00 \mathrm{~d}$ & - & $18,20 \mathrm{c}$ & $92,25 \mathrm{c}$ & - \\
\hline AQ10 WG & $70 \mathrm{~g}$ & $1,26 \mathrm{c}$ & $28,98 \mathrm{c}$ & 69,5 & $0,24 \mathrm{a}$ & $6,05 \mathrm{a}$ & 93,4 \\
\hline Solfan PK & $0,5 \%$ & $0,48 \mathrm{~b}$ & $11,45 \mathrm{~b}$ & 87,9 & $0,96 \mathrm{~b}$ & $20,32 \mathrm{~b}$ & 78,0 \\
\hline Nimrod 250 EC & 1,51 & $0,06 \mathrm{a}$ & $1,72 \mathrm{a}$ & 98,2 & $0,27 \mathrm{a}$ & $6,16 \mathrm{a}$ & 93,3 \\
\hline Score $250 \mathrm{EC}$ & 0,21 & $0,45 \mathrm{~b}$ & $10,67 \mathrm{~b}$ & 88,8 & $0,78 \mathrm{ab}$ & $16,24 b$ & 82,4 \\
\hline
\end{tabular}

Analizę statystyczną przeprowadzono oddzielnie dla każdego parametru, średnie oznaczone tą samą literą nie różnią się istotnie przy p $=0,05$ Statistical analysis was performed separately for each parameter, means followed by the same letter are not significantly different at $\mathrm{p}=0.05$

Tabela 2. Skuteczność fungicydów i nowych produktów w zwalczaniu amerykańskiego mączniaka agrestu (S. mors-uvae) na porzeczce czarnej

Table 2. The effectiveness of fungicides and new products in control of American powdery mildew (S. mors-uvae) on black currant

\begin{tabular}{|c|c|c|c|c|c|c|c|}
\hline \multirow[b]{2}{*}{$\begin{array}{c}\text { Kombinacje } \\
\text { Treatments }\end{array}$} & \multirow[b]{2}{*}{$\begin{array}{c}\text { Dawka } \\
\text { na } \\
1 \text { ha } \\
\text { Dose per } \\
1 \text { ha }\end{array}$} & \multicolumn{3}{|c|}{ I ocena -1 st. assessment } & \multicolumn{3}{|c|}{ II ocena -2 nd. assessment } \\
\hline & & $\begin{array}{c}\text { powierzchnia liści } \\
\text { zajęta przez grzyb } \\
\text { w \% } \\
\text { surface of leaves } \\
\text { covered by fungus } \\
\text { in } \%\end{array}$ & $\begin{array}{c}\text { procent } \\
\text { porażonych } \\
\text { pędów } \\
\text { per cent of } \\
\text { infected shoots }\end{array}$ & $\begin{array}{c}\text { efektywność } \\
\text { effectiveness } \\
{[\%]}\end{array}$ & \begin{tabular}{|} 
powierzchnia liści \\
zajęta przez grzyb \\
w $\%$ \\
surface of leaves \\
covered by \\
fungus in $\%$
\end{tabular} & $\begin{array}{c}\text { procent } \\
\text { porażonych } \\
\text { pędów } \\
\text { per cent of } \\
\text { infected shoots }\end{array}$ & $\begin{array}{c}\text { efektywność } \\
\text { effectiveness } \\
{[\%]}\end{array}$ \\
\hline
\end{tabular}

\begin{tabular}{l|c|c|c|c|c|c|c}
\hline $\begin{array}{l}\text { Kontrola } \\
\text { Check }\end{array}$ & & $7,73 \mathrm{~b}$ & $66,15 \mathrm{~d}$ & - & $13,16 \mathrm{c}$ & $69,01 \mathrm{~d}$ & - \\
\hline AQ 10 WG & $70 \mathrm{~g}$ & $1,35 \mathrm{a}$ & $22,87 \mathrm{c}$ & 65,4 & $2,34 \mathrm{~b}$ & $26,98 \mathrm{c}$ & 60,9 \\
\hline Solfan PK & $0,5 \%$ & $0,72 \mathrm{a}$ & $13,93 \mathrm{~b}$ & 78,9 & $1,20 \mathrm{ab}$ & $16,49 \mathrm{bc}$ & 76,1 \\
\hline $\begin{array}{l}\text { Nimrod } \\
250 \mathrm{EC}\end{array}$ & 1,51 & $0,12 \mathrm{a}$ & $3,68 \mathrm{a}$ & 94,4 & $0,75 \mathrm{a}$ & $11,37 \mathrm{~b}$ & 83,5 \\
\hline $\begin{array}{l}\text { Score } \\
250 \mathrm{EC}\end{array}$ & 0,21 & $0,08 \mathrm{a}$ & $2,63 \mathrm{a}$ & 96,0 & $0,85 \mathrm{a}$ & $8,00 \mathrm{ab}$ & 88,4 \\
\hline $\begin{array}{l}\text { Signum } \\
33 \mathrm{WG}\end{array}$ & $1,8 \mathrm{~kg}$ & $0,06 \mathrm{a}$ & $0,87 \mathrm{a}$ & 98,7 & $0,21 \mathrm{a}$ & $3,06 \mathrm{a}$ & 95,6 \\
\hline
\end{tabular}

\begin{tabular}{|c|c|c|c|c|c|c|c|}
\hline \multicolumn{8}{|c|}{2012} \\
\hline $\begin{array}{l}\text { Kontrola } \\
\text { Check }\end{array}$ & & $5,16 \mathrm{c}$ & $69,14 \mathrm{~d}$ & - & $11,07 \mathrm{~d}$ & $70,79 \mathrm{~d}$ & - \\
\hline AQ $10 \mathrm{WG}$ & $70 \mathrm{~g}$ & $1,65 \mathrm{~b}$ & $27,24 \mathrm{c}$ & 60,6 & $1,80 \mathrm{c}$ & $29,48 \mathrm{c}$ & 58,4 \\
\hline Solfan PK & $0,5 \%$ & $0,78 \mathrm{a}$ & $15,98 \mathrm{~b}$ & 76,9 & $1,20 \mathrm{~b}$ & $19,97 \mathrm{~b}$ & 71,8 \\
\hline $\begin{array}{l}\text { Nimrod } \\
250 \text { EC }\end{array}$ & 1,51 & $0,18 \mathrm{a}$ & $3,74 \mathrm{a}$ & 94,6 & $0,30 \mathrm{a}$ & $5,49 \mathrm{a}$ & 92,2 \\
\hline $\begin{array}{l}\text { Score } \\
250 \mathrm{EC}\end{array}$ & 0,21 & $0,30 \mathrm{a}$ & $5,49 \mathrm{a}$ & 92,1 & $0,30 \mathrm{a}$ & $5,98 \mathrm{a}$ & 91,6 \\
\hline
\end{tabular}

Analizę statystyczną przeprowadzono oddzielnie dla każdego parametru, średnie oznaczone tą samą literą nie różnią się istotnie przy p $=0,05$ Statistical analysis was performed separately for each parameter, means followed by the same letter are not significantly different at $p=0.05$ 
skuteczność nawozu Solfan PK W ochronie roślin ozdobnych przed rdzą (Wojdyła i wsp. 2010a) i szarą pleśnią (Wojdyła i wsp. 2011). Podjęto również próby wyjaśnienia mechanizmu działania węglanu potasu. Traynor (2009) podaje, że związek ten w środowisku wodnym ulega przemianie do wodorowęglanu, który wykazuje wysoką efektywność w zwalczaniu mączniaków prawdziwych. Obserwacje mikroskopowe pozwoliły stwierdzić, że Solfan PK powoduje bardzo silne odwodnienie, deformacje oraz kurczenie się strzępek, trzonków konidialnych oraz zarodników grzyba Sphaerotheca pannosa, a zmiany te nie były odwracalne po kontakcie grzybni i zarodników z wodą (Wojdyła i wsp. 2010a). Natomiast działanie nadpasożyta A. quisqualis w zwalczaniu chorób roślin nie jest tak jednoznaczne. Dane literaturowe podaja, że A. quisqualis, w naturalnych warunkach, zasiedla ponad 64 gatunki grzybów należących do 10 rodzajów, występujących na 256 gatunkach roślin (Falk i wsp. 1995). Wielu autorów podkreśla, że A. quisqualis rozwija się w grzybni, oidiach i kleistotecjach żywiciela, jednak nie ogranicza stopnia infekcji powodowanej przez grzyby z rzędu Erysiphales, a jedynie może ograniczać poziom zimującego inokulum (Falk i wsp. 1995; Kiss i wsp. 2010; Sucharzewska i wsp. 2011). Inni autorzy podają, że nadpasożyt ten redukuje zarodnikowanie i wytwarzanie klejstotecjów i jest w stanie zniszczyć kolonie sprawców mączniaków prawdziwych. Jednocześnie fungicydy stosowane przeciwko mączniakom prawdziwym są relatywnie mało toksyczne w stosunku do A. quisqualis, dlatego możliwe jest stosowanie go pomiędzy zabiegami fungicydowymi (Sundheim 1982; Sztejnberg i wsp. 1989; Ranković 1997).

\section{Wnioski / Conclusions}

1. Przeprowadzone badania wykazały, że nawóz dolistny Solfan PK oraz preparat biologiczny AQ 10 WG ograniczają występowanie amerykańskiego mączniaka agrestu na porzeczce czarnej i agreście oraz mogą być uzupełnieniem konwencjonalniej ochrony plantacji przed tą chorobą.

2. Ze względu na ograniczony asortyment fungicydów zarejestrowanych do ochrony przed mączniakiem na porzeczce i agreście, istnieje potrzeba kontynuowania badań i poszukiwania nowych, bezpiecznych dla środowiska środków oraz metod.

Opracowanie wykonano $\mathrm{w}$ ramach zadania $\mathrm{nr} 1.7$ „Monitorowanie występowania oraz opracowanie metod zapobiegania rozprzestrzenianiu się nowych dla warunków Polski i szczególnie szkodliwych agrofagów na plantacjach roślin jagodowych”, Programu Wieloletniego „Rozwój zrównoważonych metod produkcji ogrodniczej w celu zapewnienia wysokiej jakości biologicznej i odżywczej produktów ogrodniczych oraz zachowania bioróżnorodności środowiska i ochrony jego zasobów", finansowanego przez Ministerstwa Rolnictwa i Rozwoju Wsi.

\section{Literatura / References}

Adamska I., Czerniawska B. 2010. Nadpasożyty mączniaków prawdziwych roślin uprawnych i dzikorosnących Pojezierza Bobolickiego. Prog. Plant Prot./Post. Ochr. Roślin 50 (2): 869-873.

Broniarek-Niemiec A., Bielenin A. 2010. Komentarz do programu ochrony porzeczki i agrestu przed chorobami. s. 50-54. Ogólnopolska Konferencja Nauka Praktyce. Uprawa Porzeczek i Agrestu. Skierniewice, 20 kwietnia 2010, 97 ss.

Clement D.L., Gill A.A., Potts W.1994. Alternatives for powdery mildew control on lilac. J. Arboriculture 20 (4): $227-230$.

Falk P.S., Gadoury D.M., Cortesi P., Pearson R.C., Seem R.C. 1995. Parasitism of Uncinula necator Cleistothecia by the Mycoparasite Ampelomyces quisqualis. Pytopathology 85 (7): 794-800.

Fallik E., Ziv O., Grnberg S., Alkalai S., Klein J.D. 1997. Bicarbonate solutions control powdery mildew (Leveillula taurica) on sweet red pepper and reduced the development of postharvest fruit rotting. Phytoparasitica 25 (1): 41-43.

Kiss L., Pintye A., Zseli G. 2010. Microcyclic conidiogenesis in powdery mildews and its association with intracellular parasitism by Ampelomyces. Eur. J. Plant Pathol. 126: 445-451.

Reuveni M., Agapov V., Reuveni R. 1994. Effect of foliar spray of phosphates on powdery mildew (Sphaerotheca pannosa var. rosae) on roses. J. Phytopathol. 142: 331-337.

Ranković B. 1997. Hyperparasites of the genus Ampelomyces on powdery mildew fungi in Serbia. Mycopathologia 139: 157-164.

Sucharzewska E., Dynowska M., Kempa A.B. 2011. Occurrence of the fungi from the genus Ampelomyces - hyperparasites of powdery mildews (Erysiphales) ifesting trees and bushes in the municipal environment. Acta Societatis Botanicorum Poloniae 80 (2): $169-174$.

Sundheim L. 1982. Control of cucumber powdery mildew by the hyperparasite Ampelomyces quisqualis and fungicides. Plant Pathol. 31: 209-214.

Sztejnberg A., Galper S., Mazar S., Lisker N. 1989. Ampelomyces quisqualis for biological control and integrated of powdery mildews in Israel. J. Phytopathol. 124: 285-295.

Traynor J. 2009. Making „K” pay in your vineyard; Dropping potassium carbonate into the system. www.beesource.com/point-ofview/joe-traynor/making-k-pay-in-your-vineyard-dripping-potassium-carbonate-into-the-system, accessed: 28.12.2012.

Wojdyła A., Wieczorek W., Świętosławski J. 2010a. Solplant PK nowy nawóz do ochrony malwy i wierzby przed rdzą. Zesz. Probl. Post. Nauk Rol. 554: 315-321.

Wojdyła A., Wieczorek W., Świętosławski J. 2010b. Nawóz do ochrony róż przed mączniakiem prawdziwym. Prog. Plant Prot./Post. Ochr. Roślin 50 (1): 402-405.

Wojdyła A., Wieczorek W., Świętosławski J. 2011. Nawóz powodujący obniżenie występowania szarej pleśni w roślinach ozdobnych. Prog. Plant Prot./Post. Ochr. Roślin 51 (3): 1212-1216. 